\title{
SLMA Guidelines and Information on Vaccines
}

\author{
Fifth Edition 2014, 220 pages \\ Published by Sri Lanka Medical Association
}

Ceylon Medical Journal 2015; 60: 166

First published in 2001, the SLMA guidelines and information on vaccines fills a vacuum that cannot be filled easily in Sri Lanka. It became popular as soon as it was published. The book gained wide acceptance as the reference standard for almost all vaccine related questions encountered in day to day practice. I have carried a copy of the pocket guide during my practice for the last 14 years.

The fifth edition was published in 2014 by the same group of experts who compiled the fourth edition and is a commendable achievement. The new edition gives a lot of practical information to practitioners and it takes away the need to browse the internet.

The latest edition has two additional chapters; the first is on the immunological basis of vaccination and the second an important chapter on immunisation in the elderly. The chapter on the immunological basis of vaccination takes us through theories of immunology and the scientific basis for vaccination. Science has now discovered fine details about how $\mathrm{T}$ cells, B cells and cytokines interact with microbes and antigens in producing immunological reactions. This chapter gives new information in these areas for the busy practitioners to read at leisure or while at work. It also describes how this knowledge has influenced vaccine production techniques. Readers are also informed about the future of the vaccine industry.

Developed countries recommend vaccination against certain vaccine preventable diseases for the elderly with comorbid medical conditions. However this is not routine practice in Sri Lanka. In those countries the mortality and morbidity in elderly due to these infectious disease have come down. The life expectancy has gone up to eighties and one contributory factor is vaccination against influenza and pneumococcus with polysaccharide vaccines. It is well known that diabetics aged more than 60 years benefit from these vaccinations. Even the healthy elderly population benefit by vaccination. It reduces the hospitalisation costs of the elderly. This chapter is an eye opener and I believe it will promote a dialogue on the subject.

The chapter on surveillance and prevention of adverse events following immunization (AEFI) has been modified. It explains surveillance system in detail. Although relevant chapters describe the need for post exposure passive immunisation for protection against specific diseases there is minimal repetition. Many other chapters have been revised with new information. Current status of the meningococcal vaccine especially vaccination against type $B$ antigen and vaccine derived polio and early diagnosis of HIV with DNA-PCR are some examples. Despite these updates, the size has not expanded and it can be used as a pocket guide or an office guide.

SLMA committee on communicable diseases and Dr. Lucian Jayasuriya who spearheads this activity should be commended for a job well done.

S Amarasena, Department of Paediatrics, University of Ruhuna, Karapitiya, Sri Lanka. 